Acta Cryst. (1954). 7, 588

\title{
Refinement of the Crystal Structure of Oxamide
}

\author{
By E. M. Ayerst and J. R. C. Duke \\ Explosives Research and Development Establishment, Ministry of Supply, London W.C. 2, England
}

(Received 19 March 1954 and in revised form 14 April 1954)

\begin{abstract}
The X-ray determination of the crystal structure of oxamide has been refined, using three-dimensional Fourier and differential-synthesis methods applied to data obtained with Mo $K \alpha$ radiation; the results have been corrected for series-termination error, and it is estimated that the standard deviation of position of an atom is $0.003 \AA$.
\end{abstract}

The principal bond lengths and their estimated standard deviations are:

$$
\mathrm{C}-\mathrm{C}=1.542 \pm 0.006 \AA ; \mathrm{C}-\mathrm{O}=1.243 \pm 0.004 \AA ; \mathrm{C}-\mathrm{N}=1.315 \pm 0.004 \AA .
$$

When the present work on oxamide was commenced, the only published report dealing with $\mathrm{X}$-ray work on this substance was by Misch \& van der Wijk (1938), and owing to the unusual $\mathrm{C}-\mathrm{C}$ bond length reported by these authors it was decided to carry out a complete re-investigation of the structure using two- and three-dimensional methods; when our final refinement of the structure was approaching completion, a preliminary report of a further structural investigation was published by Romers (1953). We have employed three-dimensional Fourier and differential syntheses methods, and the results remove the anomaly of the C-C bond length reported by Misch \& van der Wijk, but the general features of the structures previously reported are confirmed.

The crystals were grown from water solution at approximately $70^{\circ}$ C., and appeared as radiating clusters or interlacing nets of laths and needles, elongated along $[a]$; the identity of this material with the common microcrystalline powder form of oxamide was demonstrated by means of $\mathrm{X}$-ray powder photographs in a $19 \mathrm{~cm}$. camera. The lattice parameters of the triclinic cell used in this work are:

$$
\begin{gathered}
a=3 \cdot 625, b=5 \cdot 188, c=5 \cdot 658 \AA \\
\alpha=83 \cdot 7, \beta=114 \cdot 1, \gamma=115 \cdot 1^{\circ} ; \\
\left(\lambda \mathrm{Cu} K \alpha_{1}=1 \cdot 5405 \AA\right) .
\end{gathered}
$$

These values were determined by an adaptation of the $\theta$-method of Weisz, Cochran \& Cole (1948), using a Weissenberg goniometer, but extrapolation methods were not employed. The calculated density for one molecule/cell is $1.667 \mathrm{g.cm} .^{-3}$, in agreement with the reported value of $1.667 \mathrm{g.cm} .^{-3}$ (Groth, 1906-19). No systematic absences of $\mathrm{X}$-ray reflexions were observed and tests for piezo-electric properties in a sensitive apparatus of the Giebe \& Scheibe type, modified from a design by Perdok \& van Suchtelen (1948) gave a negative result. Towards the end of the analysis the statistical distribution test (Howells, Phillips \& Rogers, 1950) was applied to the experimental results, but gave an indeterminate result, the plot progressing smoothly from the non-centrosymmetric curve to the centrosymmetric curve with increasing $z$; it appears, however, that the necessary conditions for application of this test are not fulfilled, for, following a suggestion of Dr D. W. J. Cruickshank, it was subsequently found that when the test was applied to the calculated results of the analysis in which space group $P \overline{1}$ had been assumed, the plot was approximately the same as that obtained with the experimental results. No evidence of rotatory polarization could be found on examining the crystals with the polarizing microscope; supporting evidence was sought by examination of a saturated water solution of the crystals in a polarimeter, again with negative results. These results were considered to justify the assumption that the space group of oxamide was $P \overline{1}$; it followed that the molecule possessed a centre of symmetry, which was chosen to be at $\left(0, \frac{1}{2}, \frac{1}{2}\right)$. $\mathrm{Cu} K \alpha$ radiation was used for the initial investigation but reflexions of medium intensity were then observed up to $\sin \theta / \lambda=0.64$; therefore the intensities were re-determined using Mo $K \alpha$ radiation, when reflexions were observed up to $\sin \theta / \lambda=1.08$. Intensities were determined visually from Weissenberg and oscillation photographs, using a multiplefilm technique with copper screens; no correction for absorption was applied, owing to the low absorbing power of the crystals for the radiation employed.

Patterson $F^{2}$ syntheses projected on (100) and (001) could be unambiguously interpreted, and the approximate co-ordinates so derived were refined by Fourier $F$ projections on the same planes; further refinement was carried out using three-dimensional

\begin{tabular}{|c|c|c|c|}
\hline Atom & $\begin{array}{c}\varrho_{\text {max. }} \text { (obs.) } \\
\text { (Differential } \\
\text { synthesis) } \\
\left(\Theta . \AA^{-3}\right)\end{array}$ & $\begin{array}{c}B \times 10^{16} \\
\left(\mathrm{~cm} .{ }^{2}\right)\end{array}$ & $\begin{array}{c}\varrho_{\text {max }} \\
\text { (Fourier) } \\
\left(\text { e. } \AA^{-3}\right)\end{array}$ \\
\hline 0 & $20 \cdot 01$ & $2 \cdot 055$ & $19 \cdot 97$ \\
\hline $\mathbf{N}$ & $17 \cdot 89$ & $2 \cdot 055$ & $17 \cdot 65$ \\
\hline C & $17 \cdot 45$ & $1 \cdot 698$ & 17.09 \\
\hline
\end{tabular}
Fourier $F$ sections parallel to (100). The subsequent refinement was carried out using three-dimensional

Table 1. Peak electron densities 
Table 2. Final co-ordinates

$\begin{array}{ccc}\text { Atom } & x & \text { S.d. } \\ \mathrm{O} & -0.0061 & 0.00099 \\ \mathrm{~N} & -0.0032 & 0.00105 \\ \mathrm{C} & -0.0025 & 0.00099\end{array}$

differential syntheses, computed on the electronic digital computer of the University of Manchester; the methods used have been described by Ahmed \& Cruickshank (1953). Initially, an experimental mean atomic scattering curve was employed, assuming $f_{\mathrm{O}}: f_{\mathrm{N}}: f_{\mathrm{C}}=8: 7: 6$, but in the concluding stages the McWeeny (1951) curves for individual atoms were employed; individual $B$ factors were suitably chosen to make the mean ratio of the electron-density curvatures for an atom, in the calculated and observed syntheses, approximately equal to the ratio of the peak electron densities in the two syntheses. The peak electron densities (not corrected for termination-ofseries error) derived from the last synthesis are given in Table 1 ; also included are the peak electron densities derived from the three-dimensional Fourier syntheses.

The $B$ factors used in the last differential synthesis are also given in Table 1; comparison of these values with those used in the previous synthesis suggests that the true values are rather less than those given in Table 1 , viz. about 1.7-1.8 $\AA^{2}$ for oxygen and nitrogen and 1.4-1.5 $\AA^{2}$ for carbon. The higher peak electron densities obtained from the differential synthesis are probably due to the better refinement of the structure at the end of the analysis.

The final atomic co-ordinates for one half of the molecule, corrected for termination-of-series error, are given in Table 2 ; in this table are given also the estimated standard deviations of the atomic coordinates (Cruickshank, 1949), calculated using the expressions for an orthorhombic lattice.

The mean value of the s.d. of position of an atom was taken to be $0.003 \AA$, which is thought to be the best value yet recorded for a structure of this kind, despite the fact that standard photographic methods of intensity estimation were used; factors which contribute to the accuracy attained are the small cell, the small thermal motion, and the use of molybdenum radiation.

Calculated bond lengths and angles, and the corresponding estimated standard deviations (Cruickshank, 1949; Cruickshank \& Robertson, 1953) are given in Table 3.

\section{Table 3. Bond lengths and angles}

\begin{tabular}{|c|c|c|}
\hline Atoms & $\begin{array}{l}\text { Bond length } \\
\text { or angle }\end{array}$ & $\begin{array}{l}\text { Standard } \\
\text { deviation }\end{array}$ \\
\hline $\mathrm{C}-\mathrm{C}$ & $1.542 \AA$ & $0.006 \AA$ \\
\hline $\mathrm{C}-\mathrm{O}$ & $1 \cdot 243$ & \\
\hline $\mathrm{C}-\mathrm{N}$ & $1 \cdot 315$ & 0.004 \\
\hline $\begin{array}{lll}N & \cdots & O \\
N & \cdots & O\end{array}$ & $2 \cdot 941$ & \\
\hline$\underset{\mathrm{C}-\mathrm{C}-\mathrm{O}}{\mathrm{N} \cdots \mathrm{O}}$ & $\begin{array}{r}2 \cdot 949 \\
119 \cdot 5^{\circ}\end{array}$ & \\
\hline $\mathrm{C}-\mathrm{C}-\mathrm{N}$ & $114 \cdot 8$ & $0 \cdot 3^{\circ}$ \\
\hline $\mathrm{O}-\mathrm{C}-\mathrm{N}$ & $125 \cdot 7$ & \\
\hline
\end{tabular}

S.d.
$0 \cdot 00046$
$0 \cdot 00050$
$0 \cdot 00048$

$\begin{array}{cc}z & \text { S.d. } \\ 0.2832 & 0 \cdot 00060 \\ -0.2371 & 0 \cdot 00062 \\ 0.3638 & 0.00058\end{array}$

S.d. 0.00062 $0 \cdot 2371$

$0 \cdot 00058$

An attempt was made to locate the hydrogen atoms in the three-dimensional Fourier sections, and also in an $\left(F_{o}-F_{c}\right)$ synthesis, but the results were not considered to be sufficiently definite to be trustworthy, and the hydrogen atoms were not included when calculating the structure factors. The final value of $R$ including all observed reflexions (738) was $0 \cdot 180$; including only those reflexions having $\sin \theta<0.45$ (i.e. which would have been observed with $\mathrm{Cu} K \alpha$ radiation), this was reduced to $0 \cdot 132$.*

The $\mathrm{C}-\mathrm{C}$ bond appears, from its length, to be of normal single type (cf. $\mathrm{C}-\mathrm{C}=1.5445 \AA$ in diamond) but the lengths of the $\mathrm{C}-\mathrm{O}$ and $\mathrm{C}-\mathrm{N}$ bonds indicate a resonance structure for the molecule in which these bonds possess a high degree of double-bond character; these results are in agreement with those reported for dithio-oxamide (Long, Markey \& Wheatley, 1954) $\alpha$-anhydrous oxalic acid (Cox, Dougill \& Jeffrey, 1952) and oxalic acid dihydrate (Ahmed \& Cruickshank, 1953). To a very close approximation, the molecule lies in the plane $x=0$; it is inferred from the calculated intermolecular $\mathrm{NH} \cdots \mathrm{O}$ distances that hydrogen bonds link the molecules into sheets parallel to this plane, but there appear to exist only relatively weak attractions of van der Waals type between these sheets. The hydrogen bonds are of two kinds, which are closely similar in length; each molecule participates in the formation of four bonds of each type, making a total of eight to each molecule. However, application of the statistical tests of significance to the $x$ co-ordinates shows that the deviation of the molecule from the plane $x=0$ must be regarded as real, and it would be more accurate to say that the plane of the molecule is slightly tilted about an axis perpendicular to the $c$ axis; the angle of tilt is about $0.7^{\circ}$, and the deviations of atoms from this plane are not significant (deviation of an atom $\leqslant 1.8 \sigma$ ).

Molecules which are in successive layers and which are related by the $a$ translation are stacked relatively compactly, each oxygen atom lying between the two carbon atoms of a neighbouring molecule in the stack; the $\mathrm{C} \cdots \mathrm{O}$ distances are $3 \cdot 106$ and $3 \cdot 163 \AA$ respectively. The perpendicular separation of neighbouring sheets of molecules is $d_{100}$, to a close approximation, i.e. $3 \cdot 007 \AA$.

The results of the analysis are in satisfactory agree-

* A list of the observed and calculated structure factors has been deposited as Document No. 4277 with the ADI Auxiliary Publications Project, Photoduplication Service, Library of Congress, Washington 25, D.C., U.S.A. A copy may be secured by citing the Document number and by remitting $\$ 1.25$ for photoprints, or $\$ 1.25$ for $35 \mathrm{~mm}$. microfilm. Advance payment is required. Make checks or money orders payable to: Chief, Photoduplication Service, Library of Congress. 


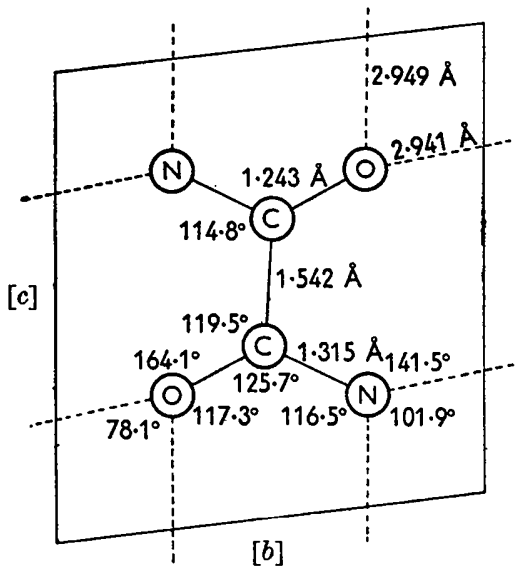

Fig. 1. The molecule lies very nearly in the plane $x=0$; hydrogen bonds link this molecule to its four neighbours in the same plane.

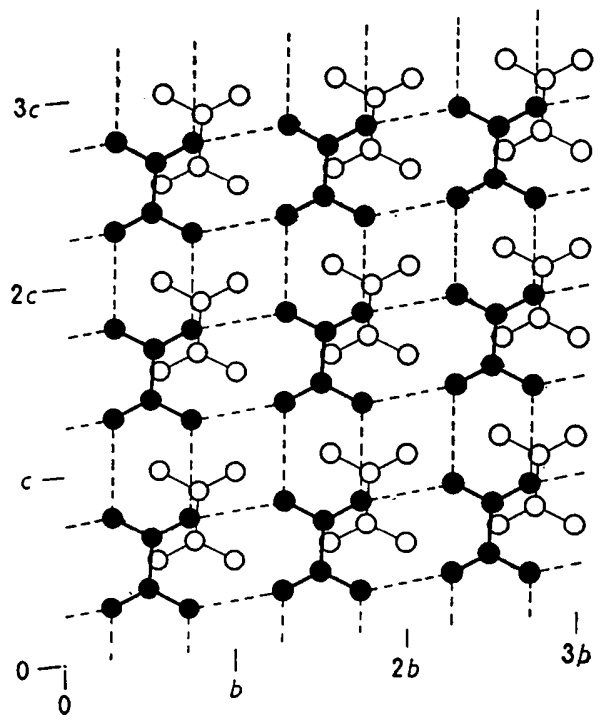

Fig. 2. Two successive layers of the structure projected per. pendicularly on to (100). Molecules which overlap are in successive layers (black circles are atoms in the upper layer) and are related by the $[a]$ translation; hydrogen bonds are denoted by broken lines.

ment with the perfect cleavage on $(100)$ and with the optical properties, the principal refractive indices for $\mathrm{Na} D$ light being:

$\alpha=1.431$ approximately perpendicular to $(100)$;

$\beta=1.636$ approximately in $(100)$ at $5^{\circ}$ to $[c]$, in acute angle;

$\gamma=1.744$ approximately in (100) at $85^{\circ}$ to $[c]$, in obtuse angle.
The observed curvatures of the electron density at the atomic peaks, in the axial directions, are as follows :

$\begin{array}{cccc} & \begin{array}{c}\partial^{2} \varrho / \partial x^{2} \\ \left(\Theta . \AA^{-5}\right)\end{array} & \begin{array}{c}\partial^{2} \varrho / \partial y^{2} \\ \left(\Theta . \AA^{-5}\right)\end{array} & \begin{array}{c}\partial^{2} \varrho / \partial z^{2} \\ \left(\Theta . \AA^{-5}\right)\end{array} \\ \mathrm{O} & 232 & 395 & 320 \\ \mathrm{~N} & 221 & 370 & 317 \\ \mathrm{C} & 251 & 382 & 330\end{array}$

The $B$ factors and the evidence of electron density, electron-density curvature and high limiting value of $\sin \theta / \lambda$ indicate that the effects of thermal motion are smaller than is usual for organic crystals; these results are in line with the stable and infusible nature of oxamide (decomposes at c. $420^{\circ}$ C.) and may be attributable at least in part to the complete linking of the molecules into sheets by the system of NH ... O hydrogen bonds.

It is a pleasure to acknowledge the valuable encouragement and help received from Prof. E. G. Cox, who kindly arranged for the work carried out on the electronic digital computer of the University of Manchester; Dr D. W. J. Cruickshank and Dr P. J. Wheatley kindly carried out these computations and grateful acknowledgment is made of much helpful suggestion and discussion during the course of the work.

The Chief Scientist, Ministry of Supply, has given permission for this paper to be published.

\section{References}

Ahmed, F. R. \& Cruickshank, D. W. J. (1953). Acta Cryst. 6, 765.

Cox, E. G., Dodgril, M. W. \& Jefrrey, G. A. (1952). J. Chem. Soc. p. 4854.

Cruickshank, D. W. J. (1949). Acta Cryst. 2, 65.

Crutckshank, D. W. J. \& Robertson, A. P. (1953). Acta Cryst. 6, 698.

Grotн, P. (1906-19). Chemische Krystallographie, vol. 4. Leipzig: Engelmann.

Howells, E. R., Philitrs, D. C. \& Rogers, D. (1950). Acta Cryst. 3, 210.

Long, B., Markey, P. \& Wheatuey, P. J. (1954). Acta Cryst. 7, 140.

MoWeENy, R. (1951). Acta Cryst. 4, 513.

MISCH, L. C. \& WIJK, A. J. A. VAN DER (1938). $C . R$. Soc. Phys. Hist. nat. Genève, 55, 96.

PerdoK, W. G. \& SUChTElen, H. VAN (1948). Appl. Sci. Res. B, 1, 195.

Romers, C. (1953). Acta Cryst. 6, 429.

Weisz, O., Cochran, W. \& Cole, W. F. (1948). Acta Cryst. 1, 83. 